\title{
An overview of the International Congress on Whiplash Associated Disorders
}

\author{
Prof Nikolai Bogduk*
}

\begin{abstract}
Introduction
Conferences such as the International Congress on Whiplash Associated Disorders, held in Berne on March 8-10, 2001, serve several purposes. Socially, they provide an opportunity for delegates to see, hear and meet leading experts in the field, and those experts get to meet one another. Academically, such conferences offer delegates a synopsis of current information, provided by plenary lectures, and the opportunity to hear or contribute new information, in the form of free papers.

A measure of the success of such a conference is the extent to which new information presented advances knowledge and understanding in the field. This essay provides an overview of the congress at hand. It compares what was known before the congress with what more was known as a result of the congress.
\end{abstract}

\section{Structure}

Whiplash entails several domains, each of which is worthy of enquiry and better understanding. These are depicted in Figures 1 and 2. The ensuing analysis of the Congress is structured around the domains depicted.

Whiplash commences with some form of commotio: an event involving the transfer of energy between a bullet vehicle and the target vehicle and its occupants. In essence, this pertains to the biomechanics of the whiplash event.

That commotio may or may not cause injury (Figure 1). That injury may or may not cause acute symptoms. Those symptoms may be contrived; they may be mild; or they may be serious.

Symptoms invite diagnosis, but the techniques used to make a diagnosis may be valid or not valid. Once a diagnosis is made, treatment follows. That treatment may be ineffective or effective; but some treatments may only seem effective, i.e. the patient recovers but not because of any specific effect of the treatment. Nevertheless, the end point of acute whiplash is that either the patient has recovered or has not.

For patients who do not recover, the cycle repeats (Figure 2). No recovery means that the patient has developed chronic symptoms. Those symptoms invite diagnosis that may or may not be valid. Treatment follows, and may or may not be effective. The patient recovers or they do not. Those patients who do not recover may become disaffected, and their chronic symptoms persist. They may be subjected to legal proceedings, which themselves may reinforce disaffection and chronicity.

\section{What We Knew Already}

The state of the art of whiplash biomechanics has been recorded in two recent, large books $(1,2)$. For clinicians, the most revealing studies have been those of McConnell and colleagues $(3,4)$, who provided detailed cinephotographic evidence of what transpires during a whiplash commotio; and those of Kaneoka et al (5), who provided high-speed, cineradiographic images of the same process. Both sets of studies showed that a cantilever motion of the head is not the basis of whiplash injury. Rather, the critical event is an upward thrust from the trunk to the cervical spine, which causes abnormal extension at lower cervical segments. It was somewhat disappointing that these studies were not given more prominence in plenary lectures at the Congress. Interested readers can consult the original studies (3-5) or a recently published review (6).

Not all patients involved in a motor vehicle accident develop neck pain. Indeed, Berglund et al (7) have shown that subjects who are involved in a motor vehicle accident but who do not develop acute neck pain maintain the same risk of chronic neck pain as does the general community who have never been involved in a motor vehicle accident. However, those subjects who suffer acute neck pain after whiplash have a three times greater risk of developing chronic neck pain. This research was not accorded any prominence at the Congress. On the other hand, the studies of Radanov et al (8) were repeatedly cited. They showed that whiplash has a good prognosis, with most patients recovering within 6 months, and more within two years; and only some $10 \%-20 \%$ of original patients develop chronic symptoms.

With respect to the diagnosis of acute whiplash, no techniques have been shown to be valid. In the vast majority of cases a patho-anatomic diagnosis of acute neck pain cannot be made on the basis of physical examination or medical imaging (9). But it could well be argued that there is no need for accurate diagnosis when the prognosis is so good.

For the treatment of acute neck pain after whiplash, systematic (10) and pragmatic (11) reviews have lamented the poor quality of the literature, and how most treatments lack a compelling evidence base. However, four studies have set a benchmark (12-15). They have shown that minimalist intervention, based on reassurance, resumption of normal activities, and home exercises, secures as good an outcome, on the average, as any more specific or traditional interventions.

* Newcastle Bone and Joint Institute, University of Newcastle, Australia

Correspondence: Professor N Bogduk, Department of Clinical Research, David Maddison Building, Royal Newcastle Hospital, Newcastle, New

South Wales, 2300, Australia. Telephone +61-2-49236172, fax +61-2-49236103, e-mail mgillam@mail.newcastle.edu.au 


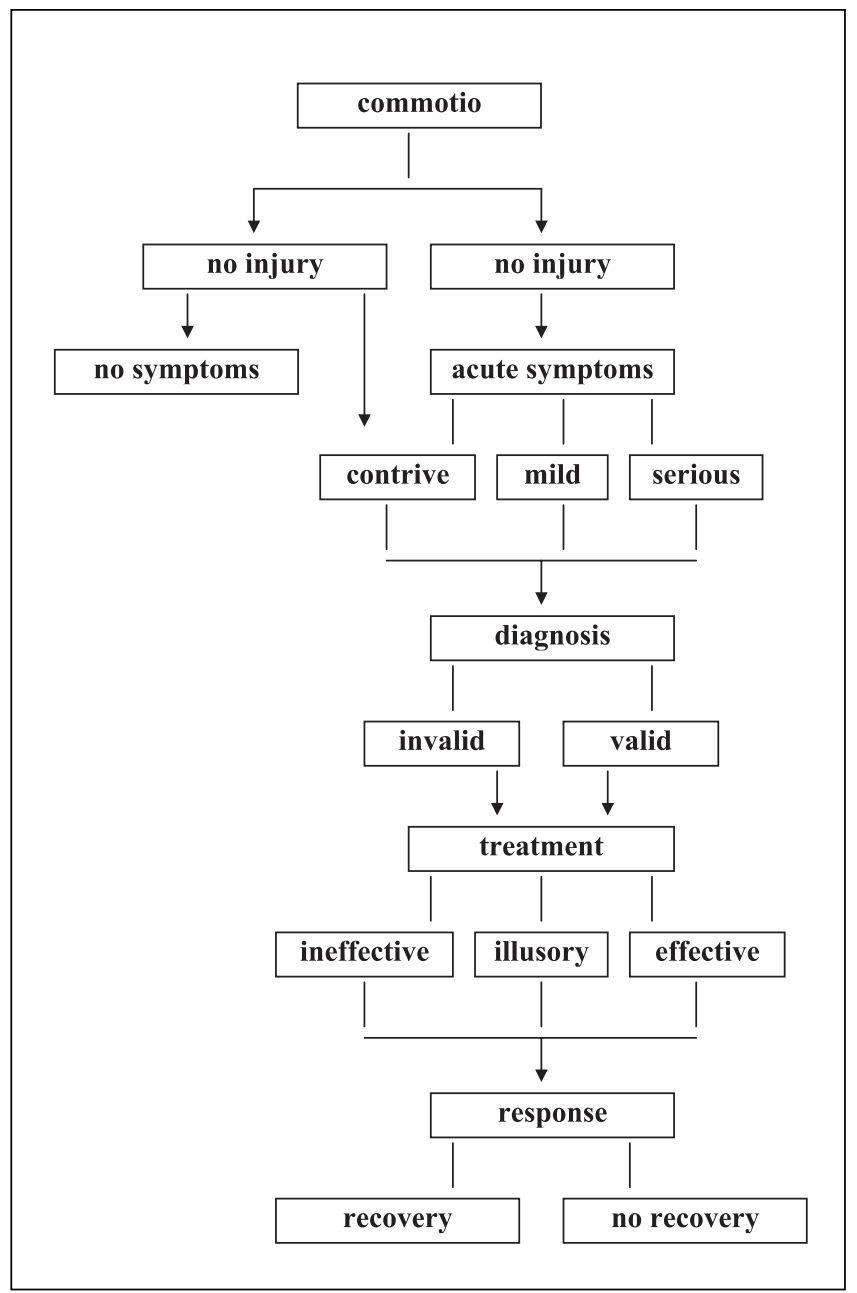

Figure 1) The domains and progression of acute whiplash and its management

For the investigation of chronic neck pain after whiplash, no conventional technique has been validated or proved useful. Radiographs and even MRI have conspicuously failed to find the "lesion" responsible (9). The one technique that has been evaluated and proven to have face validity, construct validity, and therapeutic utility, are diagnostic blocks of the cervical zygapophysial joints $(9,16-18)$.

For the treatment of chronic neck pain, no conventional or traditional intervention has been shown to be effective (9-11). Indeed, many of the more frequently practised interventions have never been subjected to study. The one technique that has survived a double-blind, placebo-controlled trial is radiofrequency neurotomy for cervical zygapophysial joint pain (19-21). Moreover, it is the only technique that has been shown to completely relieve chronic neck pain after whiplash. But this procedure has not been widely adopted.

In the absence of valid diagnostic techniques, and given the lack of proven treatment options, it should not be surprising that patients do not recover, and become disaffected. It should not be surprising that patients and their lawyers bitterly contest that there is nothing wrong with the patient.

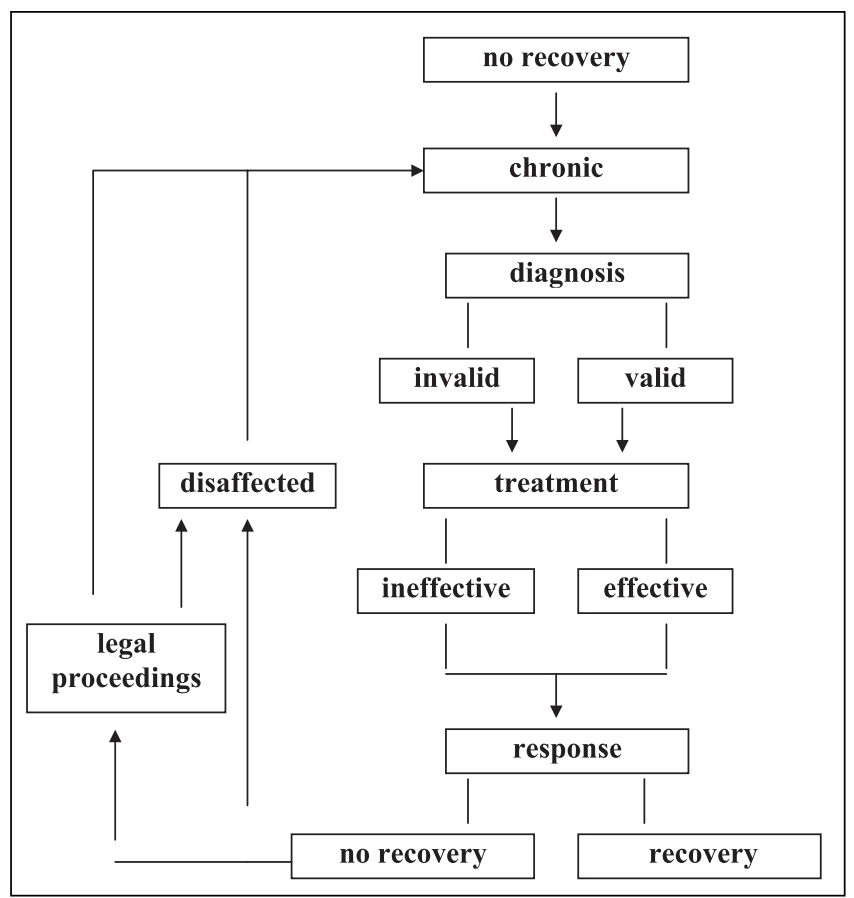

Figure 2) The domains and progression of chronic whiplash and its management

\section{New Information}

Few free papers at the Congress addressed the actual biomechanics of whiplash, or progressed our knowledge beyond what was established by McConnell $(3,4)$ and Kaneoka (5). Deng et al (22) demonstrated that shear stresses are applied to the zygapophysial joints during experimental whiplash, and argued that this may be the mechanism of injury to these joints. Castro (23) presented a revealing study that showed that normal volunteers would report symptoms after sham experimental collisions. This work underscored the importance of having control groups, even in bioengineering studies. It also highlighted how readily individuals might complain of symptoms even in the absence of injury.

A common argument used by opponents of the whiplash injury is that injuries do not occur at low impact velocities. Freeman et al (24) refuted this view by studying the incidence of injuries at a seemingly harmless ride at an amusement park. They found that injuries, including spinal cord injury, could occur at very low velocities.

Many of the free papers addressed the injuries that can occur as a result of whiplash. Studies using electromyography showed that the sternocleidomastoid reacts more to whiplash than other neck muscles (25); that the neck muscles function abnormally in whiplash patients (26); and that muscle dysfunction correlates with neck pain but not specifically or exclusively with whiplash (27). Other studies showed that some patients who suffer whiplash may have abnormal rotation of the C1-2 segment (28).

With respect to the development of symptoms, papers reported that chronicity is associated with how patients react to having been injured (29), and initial range of motion $(30,31)$. Two studies showed that patients with whiplash 
exhibit hyperalgesia $(32,33)$, and that some have impaired visual, smooth pursuit upon neck torsion (34).

No papers produced new information on the diagnosis of acute neck pain after whiplash. However, Hartwig et al (35) reported exciting initial data concerning the use of electromyography as an objective test to distinguish categorically between normal and abnormal function of neck muscles.

For the treatment of acute neck pain after whiplash, a paper reported that home exercises and advice may be sufficient treatment (36). A systematic review (37) echoed what was already apparent from the literature: that the preferred treatment is active interventions such as education, exercises, and return to normal activities.

Several papers focused on patients who develop chronic symptoms. They reported that some $12 \%$ of victims remain disabled after one year (38), although hyperalgesia did not persist as a clinical feature (39); that how patients cope is a critical factor underlying chronicity (40); and that the emotional impact of injury affects recovery (41). Some $3 \%$ of victims develop chronic cervicogenic headache (42).

A large epidemiological study showed that the principal determinants of chronicity were age, gender, crash characteristics, and the severity of initial signs (43). Another large scale population study showed, contrary to certain assertions being promoted in the literature, that the symptoms of whiplash are not consistent with a psychosocial model and with cultural factors (44).

Only one paper addressed the actual and objective diagnosis of chronic neck pain after whiplash. It reaffirmed that pain from the cervical zygapophysial joints could be diagnosed using controlled diagnostic blocks, and showed that the prevalence of zygapophysial joint pain in conventional practice was not dissimilar from that reported by research units (45). A full version of that paper had been published shortly before the Congress (46).

No papers presented at the Congress advanced our understanding of how best to treat chronic neck pain after whiplash. Whereas several studies grappled with the treatment of acute neck pain, no new controlled trials have appeared concerning chronic neck pain.

A novel and innovative contribution came from the Insurance Corporation of British Columbia (47). Representatives of this organisation described how their company had undertaken internal reforms to minimise disaffection

\section{REFERENCES}

1. Yoganandan N, Pintar FA, Larson SJ, SAnCES A (eds). Frontiers in Head and Neck Trauma. Amsterdam: IOS Press, 1998.

2. Yoganandan N, PINTAR FA (eds). Frontiers in Whiplash Trauma. Amsterdam: IOS Press. 2000.

3. McConnell WE, Howard RP, Guzman HM, et al. Analysis of human test subject kinematic responses to low velocity rear end impacts. Proceedings of the 37th Stapp Car Crash Conference, San Antonio, Texas, 1993;21-30.

4. McConnell WE, Howard RP, Van Poppel J, ET Al. Human head and neck kinematics after low velocity rear-end impactsunderstanding "whiplash". Proceedings of the 39th Stapp Car Crash Conference, Coronado, CA, 1995;215-38.

5. KANEOKA K, ONO K, InAmi S, Hayashi K. Motion analysis of cervical vertebrae during whiplash loading. Spine 1999;24:763-70.

6. BOGDUK N, YOGANANDAN N. Biomechanics of the cervical spine Part 3: minor injuries. Clin Biomech 2001;16:267-75.

7. Berglund A, Alfredsson L, Cassidy JD, Jensen I, Nygren A. The association between exposure to a rear-end collision and future neck or shoulder pain: a cohort study. J Clin Epidemiol 2000;53:1089-94. on the part of patients. They had retrained their case managers to provide greater understanding of the plight of claimants, and to help them get prompt and worthwhile medical services. This report was particularly compelling in that it showed how insurers could become part of the solution rather than being, and being perceived as, the opposition and the obstruction to rehabilitation.

\section{Discussion}

When summarising the proceedings of a large congress, one risks offending some delegates and contributors by not providing equal emphasis to all papers and contributions. Many more papers were presented than the ones cited above. However, the aims of this overview were to contrast what was previously known with new developments reported at the Congress. In doing so, only those papers that represented significant and new developments were cited, at the expense of papers that summarised or confirmed existing knowledge, or which ventured new ideas that had not yet been validated in a compelling manner.

Overall, what was evident from the Congress is that much activity continues to focus on the symptoms and signs resulting from whiplash, in terms of their epidemiology, natural history, and physiological nature, but that this work remains largely descriptive. We seem to keep describing and measuring the problem, but not doing something about it.

Some studies have continued to test various interventions for acute whiplash, even though the literature to date has strongly established that simple but active measures should be the treatment of choice. Advocates of particular regimens of treatment have not demonstrated efficacy for chronic neck pain after whiplash.

Where research activity seems to be most deficient, if not almost entirely absent, is in the diagnosis of either acute or chronic neck pain after whiplash. We have not progressed beyond diagnostic blocks being the only validated test.

It would appear, therefore, that the needs for research lie in diagnosis and treatment of chronic whiplash, whatever the nature of those interventions may be. Continuing to describe the problem and measuring it does not constitute progress. The challenge lies in doing something about it. Accordingly, the measure of success of any future Congress would be: has diagnosis improved, and has a greater proportion of patients recovered?

8. Radanov BP, Sturzenegger M, Di Stefano G. Long-term outcome after whiplash injury: a 2-year follow-up considering features of injury mechanism and somatic, radiologic, and psychosocial findings. Medicine 1995;74:281-97.

9. BogDuK N. The neck. Bailliere's Clinical Rheumatology 1999; 13:261-85.

10. Spitzer WO, Skovron ML, Salmi LR, ET AL. Scientific monograph of the Quebec task force on whiplash-associated disorders: redefining "whiplash" and its management. Spine 1995;20:1S-73S.

11. BogDuK N. Treatment of whiplash injuries. In: Malanga GA (ed). Cervical Flexion-Extension/Whiplash Injuries. Spine: State of the Art Reviews. Philadelphia: Hanley \& Belfus 1998;12:469-83.

12. MCKINNEY LA. Early mobilisation and outcomes in acute sprains of the neck. Brit Med J 1989; 299:1006-8.

13. MCKinney LA, DORnAN JO, RyAn M. The role of physiotherapy in the management of acute neck sprains following road-traffic accidents. Arch Emergency Med 1989;6:27-33.

14. Rosenfeld M, GunNARSSON R, BORENSTEIN P. Early intervention in whiplash-associated disorders. A comparison of two treatment 
protocols. Spine 2000; 25:1782-7.

15. BorChgrevink GE, KaAsa A, McDonagh D, Stiles TC, HARALDSETH O, LEREIM I. Acute treatment of whiplash neck sprain injuries: a randomized trial of treatment during the first 14 days after a car accident. Spine 1998;23:25-31.

16. BARNSLEY L, LoRd SM, WAllis BJ, BogduK N. The prevalence of chronic cervical zygapophysial joint pain after whiplash. Spine 1995;20:20-6.

17. Lord S, Barnsley L, Wallis BJ, Bogduk N. Chronic cervical zygapophysial joint pain after whiplash: a placebo-controlled prevalence study. Spine 1996;21:1737-45.

18. BOGDUK N, LORD SM. Cervical zygapophysial joint pain. Neurosurgery Quarterly 1998;8:107-17.

19. Lord SM, Barnsley L, Wallis BJ, McDonald GJ, Bogduk N. Percutaneous radio-frequency neurotomy for chronic cervical zygapophysial-joint pain. N Engl J Med 1996;335:1721-6.

20. LORD SM, MCDONALD GJ, BOGDUK N. Percutaneous radiofrequency neurotomy of the cervical medial branches: a validated treatment for cervical zygapophysial joint pain. Neurosurgery Quarterly 1998; 8:288-308.

21. MCDONALD G, LORD SM, BogduK N. Long-term follow-up of cervical radiofrequency neurotomy for chronic neck pain. Neurosurgery 1999;45:61-8.

22. Deng B, Begeman PC, Yang KH, Tashman S, King AI. Neck kinematics in rearend impacts. Paper presented at the International Congress on Whiplash Associated Disorders, Berne March 8-10, 2001.

23. CASTRO WHM. Correlation between exposure to biomechanical stress and "whiplash symptoms". Paper presented at the International Congress on Whiplash Associated Disorders, Berne, March 8-10, 2001. "Whiplash Associated disorders" - Medical, biomechanical and legal aspects. Berne 2002; 65.

24. Freeman mD, Centeno C, Croft AC, Nicodemus CN. Significant spinal injury resulting from low-level accelerations: a comparison with whiplash. Paper presented at the International Congress on Whiplash Associated Disorders, Berne, March 8-10, 2001.

25. Kumar S, Narayan Y, Amell T. An electromyographic study of low velocity rearend impacts. Paper presented at the International Congress on Whiplash Associated Disorders, Berne, March 8-10, 2001

26. Kramer M, Hartwig E, Schmid I, Strobel P, Scheich M, Kinzl L. Fine-wire EMG measurement of cervical muscles in patients with late whiplash syndrome performing isometric and dynamic exercise. Paper presented at the International Congress on Whiplash Associated Disorders, Berne, March 8-10, 2001.

27. Nederhand MJ, Hermens HJ, Ijzerman MJ, Zivold G. Is the acceleration-deceleration trauma an exclusive cause of cervical muscle dysfunction in the chronic whiplash associated disorder grade II (WAD II)? Paper presented at the International Congress on Whiplash Associated Disorders, Berne, March 8-10, 2001.

28. NidECKER A, EISENHAFT D, LAUKKANEN I. Fixed rotary distortion of the upper C-spine after whiplash evaluation from sagittal MRI images. Paper presented at the International Congress on Whiplash Associated Disorders, Berne, March 8-10, 2001.

29. Benketorp O, Olsson I, CarlsSOn SG, StyF J. Outcome of WAD predicted by MPI. Paper presented at the International Congress on Whiplash Associated Disorders, Berne, March 8-10, 2001.

30. Karlsson El, FalKheden-Henning L, Olsson I, Bunketorp O. Outcome of WAD associated with early clinical findings by a physiotherapist. Paper presented at the International Congress on Whiplash Associated Disorders, Berne, March 8-10, 2001.

31. KASCH H, BACH FW, JENSEN TS. Risk for disablement after acute whiplash injury. A one-year prospective study. Paper presented at the International Congress on Whiplash Associated Disorders, Berne, March 8-10, 2001

32. Herren R, Weiss S, Petersen-Felix S, Arendt-Nielsen L, Radanov BP, CURATOLO M. Correlation between neck pain and pressure pain threshold after whiplash injury. Paper presented at the International Congress on Whiplash Associated Disorders, Berne, March 8-10, 2001.

33. Curatolo M, Petersen-Felix S, Erendt-Nielsen L, Giani C, ZBINDEN AM, RADANOV BP. Facilitated temporal summation of nociceptive stimuli in chronic pain after whiplash injury. Paper presented at the International Congress on Whiplash Associated Disorders, Berne, March 8-10, 2001.

34. Tjell C, Terenbaum A, Sandstrom S. Smooth pursuit neck torsion test a specific test for whiplash associated disorders? Paper presented at the International Congress on Whiplash Associated Disorders, Berne, March 8-10, 2001.

35. Hartwig E, Kramer M, Schmidt I, Strobel P, SCHEICH M, KInZL L. Fine wire EMG of the cervical muscles in the diagnostic of fresh whiplash injuries and its prognostic value. Paper presented at the International Congress on Whiplash Associated Disorders, Berne, March 8-10, 2001.

36. Soderlund A, Lindberg P. Physiotherapy management of acute and chronic WAD two randomized treatment studies. Paper presented at the International Congress on Whiplash Associated Disorders, Berne, March 8-10, 2001.

37. Peeters GGM, Verhagen ap, de Bie RA, Oostendorp Rab. The efficacy of conservative treatment in whiplash patients: a systematic review of clinical trials. Paper presented at the International Congress on Whiplash Associated Disorders, Berne, March 8-10, 2001.

38. KASCh H, BACH FW, JenSEN TS. Development of pain and nonpainful complaints after acute whiplash injury. A 1-year prospective study. Paper presented at the International Congress on Whiplash Associated Disorders, Berne, March 8-10, 2001.

39. KASCH H, BACH FW, JENSEN TS. Nociceptive sensitization after whiplash injury. A one-year prospective study. Paper presented at the International Congress on Whiplash Associated Disorders, Berne, March 8-10, 2001

40. SODERLUND A, LindBerg P. Mediating and prognostic factors in long-term WAD-symptomatology. Paper presented at the International Congress on Whiplash Associated Disorders, Berne, March 8-10, 2001

41. Drottning M, StafF PH, Malt UF. The one year prevalence of post-traumatic stress response after common whiplash. Paper presented at the International Congress on Whiplash Associated Disorders, Berne, March 8-10, 2001.

42. Drottning M, Staff PH, SjaAstad O. Cervicogenic headache (CEH) after whiplash injury. Paper presented at the International Congress on Whiplash Associated Disorders, Berne, March 8-10, 2001.

43. SUISSA S. Risk factors of poor prognosis after whiplash injury. Paper presented at the International Congress on Whiplash Associated Disorders, Berne, March 8-10, 2001. "Whiplash Associated disorders" Medical, biomechanical and legal aspects. Berne, 2002:111.

44. Centeno C, Freeman MD, Croft AC. A comparison of the functional profile of an international cohort of whiplash-injured patients and non-patients: an internet study. Paper presented at the International Congress on Whiplash Associated Disorders, Berne, March 8-10, 2001.

45. SpeldeWinde G, BASHFord G, Davidson I. Diagnostic cervical zygapophyseal joint blocks for chronic cervical pain. Paper presented at the International Congress on Whiplash Associated Disorders, Berne, March 8-10, 2001.

46. SPELDEWINDE GC, BASHFord GM, DavidSon IR. Diagnostic cervical zygapophysial joint blocks for chronic cervical pain. Med J Aust 2001;174:174-6.

47. HARDER H, POTTS L. Disability management: the British Columbia experience. Paper presented at the International Congress on Whiplash Associated Disorders, Berne, March 8-10, 2001. "Whiplash Associated disorders" Medical, biomechanical and legal aspects. Berne 2002;133.

This material was presented at the International Congress on Whiplash Associated Disorders, Berne, Switzerland, March 8 to 10, 2001. The paper appeared originally in the book "Whiplash Associated Disorders" - medical, biomechanical and legal aspects, published by Staempfli Publishers Ltd,

Berne 2002. The paper is published in North America in Pain Research $\mathcal{E}$ Management with the permission of Staempfli Publishers Ltd. 


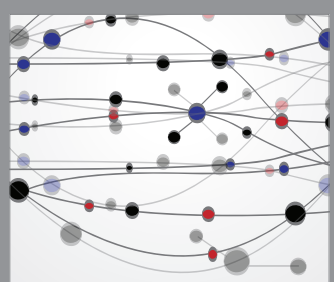

The Scientific World Journal
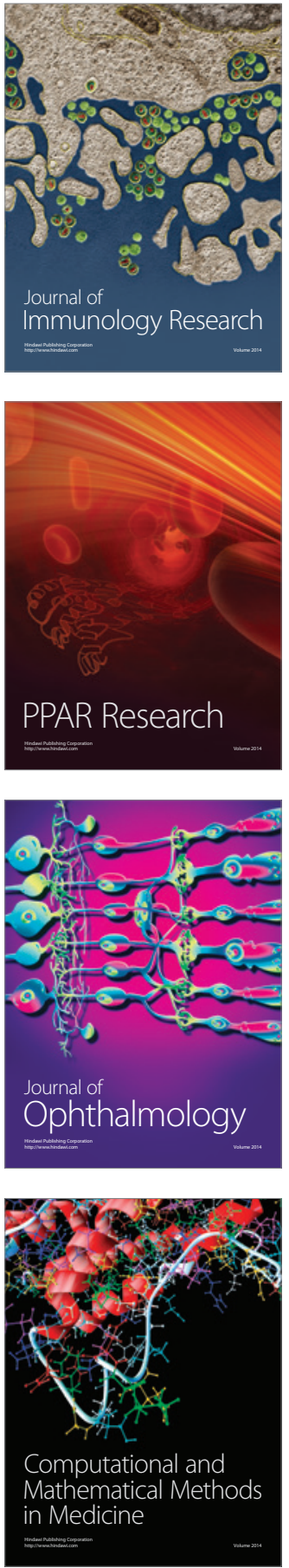

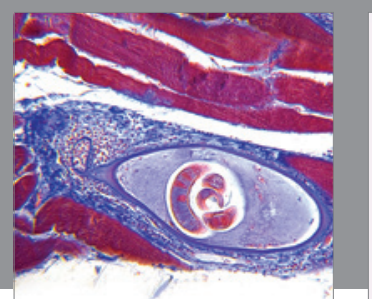

Gastroenterology Research and Practice

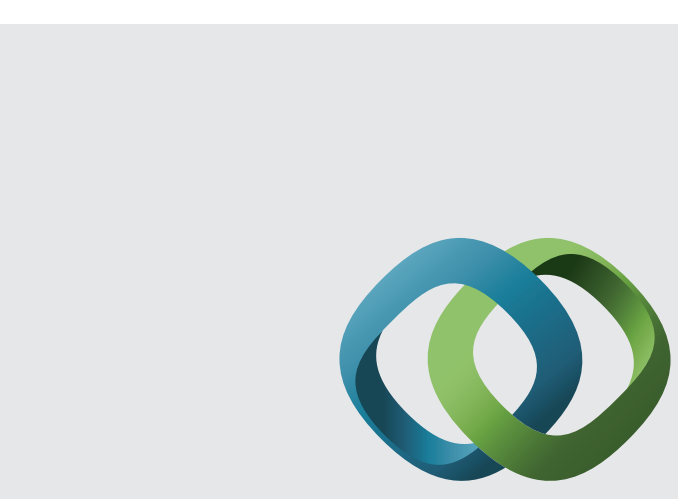

\section{Hindawi}

Submit your manuscripts at

http://www.hindawi.com
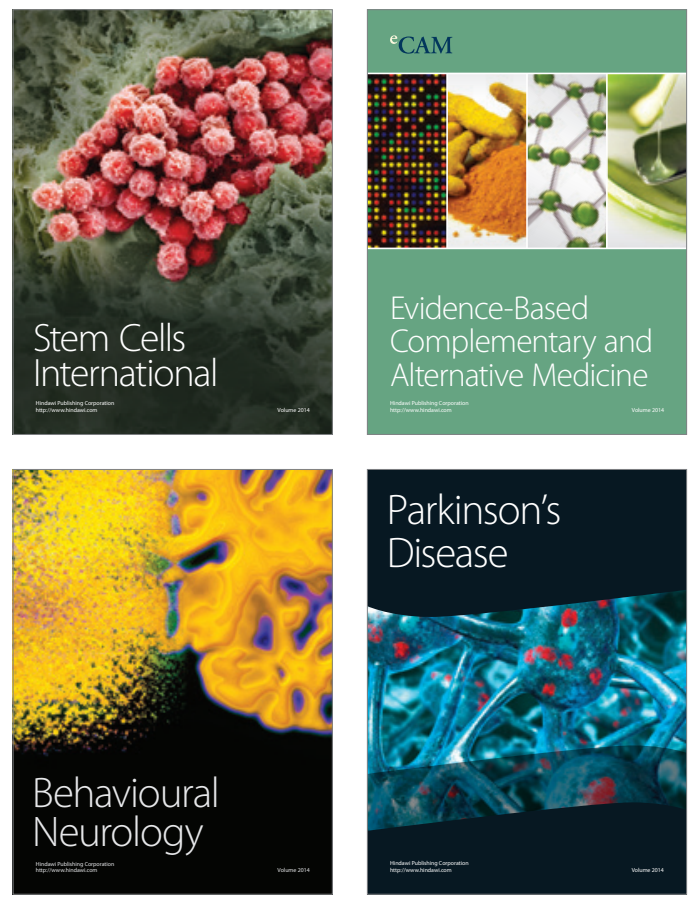
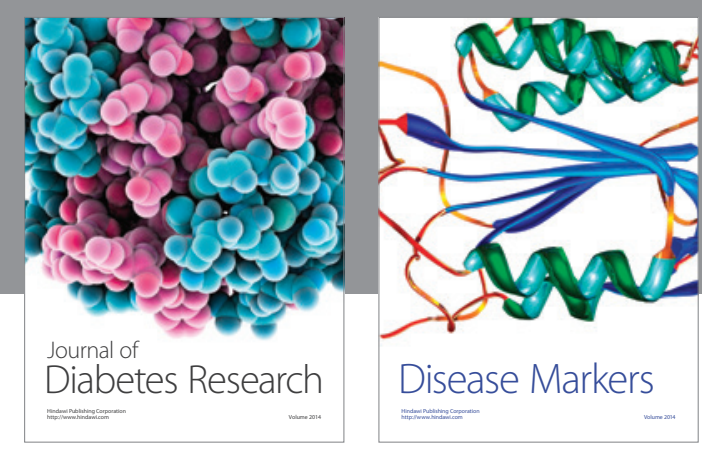

Disease Markers
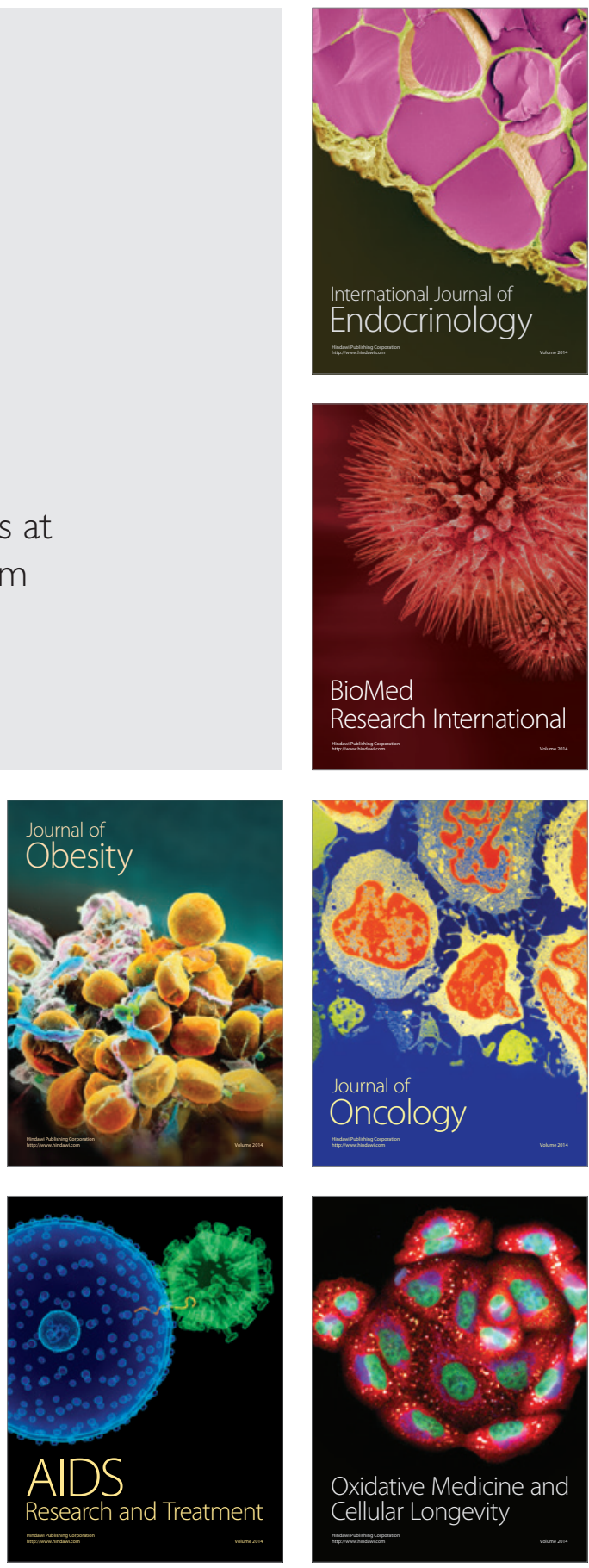